\title{
Education as a Direct Profitable Societal Investment: Innovation Pedagogy Putting Sociocultural Learning Theories into Practice in Higher Educational Institutes
}

\author{
Taru Penttiläa, ${ }^{\mathrm{a},}$, Sami Lyytinen ${ }^{\mathrm{a}, 2}$, Liisa Kairisto-Mertanen ${ }^{\mathrm{a}, 3}$, Harri Lappalainen ${ }^{\mathrm{a}, 4}$ \\ Technology, Environment and Business, Turku University of Applied Sciences, Turku, FINLAND \\ ${ }^{1}$ taru.penttila@turkuamk.fi, ${ }^{2}$ sami.lyytinen@turkuamk.fi, ${ }^{3}$ liisa.kairisto-mertanen@turkuamk.fi, \\ ${ }^{4}$ harri.lappalainen@turkuamk.fi
}

\begin{abstract}
Higher education needs to respond to the needs of employers by providing capable workforce. Graduating students have to possess capabilities to take part in diverse innovation processes at their future work places. In this paper we present how higher education can be changed to the direction where both new innovations are more evident and where education itself can serve societal needs more directly by producing generic innovation competences for students. The theoretical framework is based on innovation pedagogy, the socio-cultural theory and the constructivist view of learning. The empirical findings show how innovation pedagogy is put into practice and how applied research, development and innovation operations in HEIs can create direct benefits to the businesses and other stakeholders. As the result we state that innovation pedagogy can produce innovation competencies and simultaneously serve regional, national and international stakeholders ensuring direct societal benefits. The results are especially useful for those who want to increase the external impact of higher education institutes.
\end{abstract}

Index Terms - innovation, innovation pedagogy, innovation competence, assessment, higher education.

\section{Introduction}

Rapidly developing societies, environmental change and increasingly dynamic economies with new and often unforeseen needs from the business side call for everincreasing abilities of experts and employees of companies to produce innovations. The educational system must respond to this call at its every level. Especially higher educational institutes (HEIs) should focus more on producing direct societal benefits by using their expertise and capabilities to innovate. Universities of applied sciences, along with other higher education institutions, are under increasing societal pressure to respond to the rapidly changing requirements of working life. [1],[2]

Innovation pedagogy as a learning approach is a new way to link the everyday work at HEIs with the needs coming from the society. It aims to accelerate versatile innovation processes as well as to produce innovation competences to the students. Innovation pedagogy is based on the needs originating from the surrounding society and at the same time on where and how innovations are emerging [2]. Sociocultural learning theory forms the background for innovation pedagogy, which links different players in the society to work in cooperation with everyday day work in HEIs [3]. The cornerstones of innovation pedagogy and various opportunities to boundary crossing change the way how knowledge is assimilated, produced and used in a manner that can create sustainable innovations [2]. This paper is based on the socio-cultural theory and the constructivist view of learning developed to encompass the social and cultural customs of a particular community and its ways of operating. The study extends traditional individual based learning used in many contexts to include collaborative and networking based learning in order to support innovations.

In the future, higher education must have a bigger role as a facilitator in innovation processes carried out in cooperation with other societal players. In this paper we present how higher education can be changed to the direction where both new innovations are more evident and where education itself can serve societal needs more directly by producing generic innovation competences for students. We also show how innovation pedagogy is put into practice, how the changing role of teachers can be managed in the process and how applied research, development and innovation operations in HEIs can create direct benefits to the co-operating businesses. The results are especially useful for those who want to increase the external impact of higher education institutes.

\section{Methods - theoretical and empirical approaches}

According to innovation pedagogy, learning cannot be separated from the surrounding world, as the cultural operating models always steer learners and their activities. The relating sociocultural theories [4],[5] highlight the need to define the cultural toolkit and modus operandi of learning at a certain point in time and in a certain culture. The way we understand our surroundings and solve problems is greatly influenced by the typical activities in which we take part on a daily basis - a fact that places a special emphasis on learning environments in which pedagogical methods are applied in practice.

In addition to the central role of the learner, innovation pedagogy promotes practical activities as well as creating, constructing and cumulating knowledge. Scientific knowledge facilitates solving practical problems, but sometimes a new practice born out of immediate need in a practically oriented situation results in a scientific breakthrough. Also in the field of learning theories in general, the interplay between theory and the practices in which theories are applied can be increasingly observed. Through collaborative learning, different actors are able to work together in dialogue in such a manner that their own expertise can be efficiently shared and combined in novel ways resulting in something more than the sum of its parts. [4],[6],[7] 
A fruitful environment for innovation consists of individuals with different backgrounds working together on similar problems. These innovation communities can be tight teams meeting every day or network-like looser communities. The success of the communities is based on know-how and sharing knowledge as well as on the ability to combine different points of view and approaches. Innovations are more frequently generated where different fields of expertise meet. [2],[8]

Similarly, HEIs' research and development activities and working life cooperation should form a solid and interactive whole that can respond to the constantly changing expectations falling upon universities of applied sciences. Combining knowledge related to innovation activities on the one hand and pedagogy on the other can offer the theoretical foundation for improving expertise-based competitiveness. This process is at its most natural in the collaboration between higher education institutions and working life. It also underlines the challenge that innovation pedagogy aims to tackle by combining learning with producing and applying new knowledge. [2] In TEB, one of the methods for applying and carrying out education according to the principles of innovation pedagogy is a method called hatchery work. It combines real-life assignments, peer counselling and working in cross-disciplinary groups. [9]. Hatcheries are a good example of putting cross-disciplinarity into practice, applied already for a decade in the Faculty of Technology, Environment and Business (TEB) at TUAS and now it is spreading to other HEIs.

The first one of these hatchery methods, in a chronological order, is called Project hatchery. This compulsory study unit for all first-year Bachelor's degree students in TEB was initially launched in 2008. Nowadays there are around 45 Project hatcheries operating every autumn, involving around 450 first year students, 45 senior students and 15 teachers. All Project hatcheries are multidisciplinary, consisting of students from almost ten different degree programmes (e.g. engineering, business, design). Every hatchery is mentored by a teacher (each teacher has 3-4 hatcheries to guide) and tutored by a senior student. The role of student tutors is significant in everyday guidance and also in terms of mental support. As a reward, student tutors get credit units and a testimonial for their work. A Project hatchery operates for 3.5 months and during that period, the participating students are obligated to plan, implement, report and present their work. Hatcheries have compulsory weekly meetings and between them students work with assignments when not having any other lessons. [10]

The goals of this study unit are purely linked to the development of innovation competencies, i.e. to provide the students with generic and soft skills. The project hatchery method increases these competences and makes clear that they must be included also in other studies carried out at HEIs.

The project hatchery method has been created and launched in Finland but we strongly believe that it can be adopted in any academic organisation around the globe. The first official adaptation outside Finland was in the pilot phase at Binus University in Jakarta, Indonesia during autumn 2014. This pilot project gives us valuable evidence of the usefulness of the method as well as of the need for development.
Another hatchery method used widely at TEB is the research hatchery, which is a course for more advanced university students, taking place after the project hatchery. Unlike the Project hatchery, the Research hatchery is not an independent study unit, but rather one of the teaching methods of innovation pedagogy that enables combining research and development work as well as the university's service activities into studying and learning. [3]. The Research hatchery, like the Project hatchery, is based on social learning theories linking students' everyday work at a university more with the surrounding society. The assignments the problems to be solved come from organisations where they are really emerging and where they need to be solved, i.e. from private and public sector operators, NGOs and from different research, development and innovation projects jointly carried out with different regional players. The accepted assignments are evaluated in a way that they can offer the opportunity to link study specific goals of students' curricula with generic innovation competences. [11].

The working methods of research hatcheries are similar to the practices of working life as they resemble points of problem-based, progressive inquiry and project learning. Every hatchery is like a project that has clear goals, a schedule and defined resources, and they are usually longlasting by nature. The main thing is that research hatcheries are carried out in close cooperation with an actor outside the university (from businesses or other organisations etc.) [12].

All hatcheries are based on existing needs or problems pinpointed either at the university's own RDI operations or in some of our public or private stakeholders. The daily dialogue with the stakeholders creates a joint understanding and enables us to successfully serve the world outside of the university while still concentrating on one of our main tasks, enhancing the competencies of our students. Our students' curricula are flexible and ensure the possibility to include different hatcheries during the study path, along with other courses concentrating more on study specific skills.

Because of their nature as a bridge between the academic world and the rest of society, hatchery methods can be seen as cradles for new innovators and new innovations. While our main aim is to provide our students with competencies that enable them to successfully participate in innovation processes, already several hundred implementations of hatcheries give evidence for that we may also reach outputs that can be considered as innovations. In this context it is essential to remember our definition for innovation. We have adopted it from the official Innovation Strategy of Finland and according to it, innovation is a "utilised knowledgebased competitive advantage". A competence-based competitive advantage can emerge from scientific research, technology, business models, service solutions, design, brands or methods of organising work and production. Typically, an innovation is generated by a combination of different competencies. Capitalised as innovations, competence-based competitive advantages promote the advancement of businesses, society and wellbeing. [13] Our joint interpretation is that an innovation does not need to be something revolutionary and big. Most often innovations are incremental and they can be established in a studentcompany cooperation if partner companies are willing and able to utilise that novel source of innovation in their businesses. 


\section{Discussion}

The contribution of innovation pedagogy is to provide the students, once they are ready to enter working life, with innovation competencies which include defined knowledge, skills and attitudes needed when being involved in diverse innovation processes. The methods applied and the way teachers and students interact constitute the basis for learning and thus enable the development of innovation competences. The methods used also facilitate intuitive and unexpected learning during the learning processes and make transmitting tacit knowledge possible when dealing with working life. In innovation pedagogy the learning outcomes can manifest themselves in the format of intuitive and tacit learning taking place in the learning situation. They can be e.g. experiences of cultural differences or of working with customers.

Innovation competences are learning outcomes that refer to knowledge, skills and attitudes needed for the innovation activities to be successful. The innovation competences drawn up at TUAS follow the European Qualifications Framework (EQF) and comprise three levels: individual, interpersonal and networking innovation competences. The individual level includes e.g. independent thinking and decision-making, target-oriented and tenacious actions, creative problem-solving and development of working methods as well as self-assessment and development of one's own skills and learning methods. The students are thus able to self-assess and develop their own skills and learning methods. The interpersonal level focuses on the abilities to co-operate in a diversified team or working community, to take the initiative and to work responsibly according to the targets of the community, to work in research and development projects by applying and combining knowledge and methods of different fields, to work along the principles of ethics and social responsibility as well as to work in interactive communication situations. Finally, the networking level covers the abilities to create and maintain working connections, to work in networks, to co-operate in a multidisciplinary and multicultural environment as well as to communicate and interact in an international environment. Innovation competences are learned gradually as new information is added to the existing knowledge structures. [9]

In the assessment of innovation competencies the emphasis is performance-oriented and lies on interpersonal innovation competencies and networking innovation competencies. This sets special demands especially on the number and timing of assessments, assessment criteria and assessment methods. The first challenge is the need of several measurements during the study time in order to be able to measure the impact of teaching and learning methods in a reliable way. This involves diagnostic assessment to be added to formative and summative assessment methods to be able to define the starting level of a learner. The second challenge lies on assessment criteria; for example how to measure the ability to co-operate in a diversified team or work community or the ability to co-operate in a multidisciplinary and multicultural environment. This sets requirements also on the test environment, where the learning environment must include group processes and multidisciplinary teams. Third, the challenge is put on assessment methods; the earlier mentioned assessment methods, diagnostic, formative and summative assessment, will need several assessment tools in this context. In addition to traditional and easy to use quantitative tools such as surveys and questioning, some other tools such as participatory evaluation, collaborative dialogue, peer assessment and self-reflection come useful. Finally, there will be a need for evaluation of the enduring effects of education, before an innovation competence assessment tool will capture its reliability. This refers to evaluation of constancy of learning outcomes and real educational impacts. The final objectives of learning outcomes are not only single competencies but also their holistic adaptation to practical situations. Evaluation of the enduring effects of education can first take place after some time from the end of the studies. This kind of follow-up evaluation is done at TUAS, but its focus on innovation competence evaluation requires more specification in the future.

The development and assessment of innovation competences of students confronts teachers with unique decisions concerning teaching and learning methodology and how to assess the results of classroom efforts. Four European universities joined forces to test the effectiveness of Research Hatchery as an active learning methodology and give shape to an instrument that could aid in the development and assessment of innovation competence in a higher education setting. The venture also comprises a plan for training teachers to use the criteria, which the partners named Innovation Competencies Development (INCODE) Barometer. The set of criteria, the INCODE Barometer, can be used in self, peer and tutor assessment but, due to the complexity of the assessment, should be preceded by training that will familiarise the user with behavioural observation, errors frequently made by raters and the specific framework in which the assessment is to occur. We trust that the INCODE Barometer and the training procedure for its application will be a major contribution to higher education programmes for the development and assessment of innovation competence. Actual integration of the tool and training into curriculum design remains to be addressed. [14]

\section{Conclusion}

Different pressures coming from rapidly developing societies and highly dynamic economies puts higher educational institutes all over the globe to the situation where education must change. The competencies needed in working life in general and particularly in diverse innovation processes are the ones that show the direction to the change. Although the process is well understood, the change at HEIs is taking place slowly. In this paper we have described how innovation pedagogy handles the way that knowledge in today's expertise must be understood, how it is described in competencies and how these competencies are provided in everyday work at HEIs.

Innovation pedagogy confesses the societal needs as the basis for the work done at HEIs. Having social learning theories as a background, innovation pedagogy links university work together with the regional needs emphasising the meaning of innovation competencies without forgetting the study specific skills students must have. Innovation pedagogy emphasises the meaning of team work and multidisciplinary groups, as well as internationalisation as main sources of innovations and especially as core competencies which a today's innovator should have. Innovation pedagogy is put into practice via different activating learning methods such as hatchery methods that produce study specific and innovation competencies, and 
simultaneously serve regional, national and international operators ensuring direct societal benefits.

\section{References}

[1] Kairisto-Mertanen, Liisa (2011): Introduction. pp 7-10 In Lehto, Anttoni, Kairisto-Mertanen, Liisa \& Penttilä, Taru (ed) (2011) Towards innovation pedagogy - A new approach to teaching and learning for universities of applied sciences. Reports from Turku University of Applied Sciences 100.

[2] Penttilä, Taru; Kairisto-Mertanen, Liisa; Putkonen, Ari and Lehto, Anttoni (2013): Innovation pedagogy - a strategic learning approach for the future. pp 11-23. In Lehto, Anttoni and Penttilä, Taru (ed) (2013): Pedagocical views on innovation competences and entrepreneurship. Innovation pedagogy and other approaches. Reports from Turku University of Applied Sciences 171.

[3] Räsänen, Meiju and Lyytinen Sami (2013): Working life familiarisation through hatchery activities. pp. 57-64 In Lehto, Anttoni and Penttilä, Taru (ed) (2013): Pedagocical views on innovation competences and entrepreneurship. Innovation pedagogy and other approaches. Reports from Turku University of Applied Sciences 171 .

[4] Vygotsky Lev Semyonovich (1982): Ajattelu ja kieli. Espoo: Weilin \& Göös.

[5] Walker, Richard A., Pressick-Kilborn Kimberley, Arnold Lynette S. Sainsbury , Erica J. (2004). Investigating Motivation in Context: Developing Sociocultural Perspectives. In European Psychologist Vol 9(4), Dec, 2004, pp. 245-256.

[6] Wenger, Étienne (1998): Commun ities of Practice: Learning, meaning, and identity. New York: Cambridge University Press.

[7] Hakkarainen, Kai; Lonka, Kirsti \& Lipponen, Lasse (2001). Tutkiva oppiminen. Helsinki: WSOY.

[8] Johansson, Frans (2004): The medici effect: breakthrough insights at the intersection of ideas, concepts and cultures. Harvard Business School Press.

[9] Kairisto-Mertanen, Liisa; Räsänen, Meiju; Lehtonen, Jouko and Lappalainen, Harri (2012). Innovation pedagogy - learning through active multidisciplinary methods. Revista de Docencia Universitaria. REDU. Monográfico: Buenas prácticas docente en la enseñanza universitaria. 10 (1), 67-86.

[10] Lappalainen, Harri and Suvivuo, Pia (2014): Who gets added value from our education? Implementations of Innovation Pedagogy in Bachelor's and Master's Education in Turku University of Applied Sciences. pp. 91-99 In Stracke, Ehlers, Creelman and ShamarinaHeidenreich (eds) (2014): Changing the Trajectory. "Quality for Opening Up Education". Official Proceedings of the International EIF/LINQ Conference 2014. Logos Verlag Berlin GmbH.

[11] Räsänen, Meiju; Kairisto-Mertanen, Liisa \& Penttilä, Taru (2013). The Role of Social Learning Environment in the Context of Innovation Pedagogy in Higher Education. Proceedings of the Participatory Innovation Conference PIN-C 2013, 18th-20th June Lahti, Finland. Lappeenranta University of Technology LUT, Scientific and Expertise Publications - Research Reports No. 6.

[12] Räsänen, Meiju and Kyllönen, Annariikka (eds.) (2013): Research hatchery as a cradle for new innovators. Handbook for implementation. Course material from Turku University of Applied Sciences 84 .

[13] Aho, Esko; Brunila, Anne; Eriksson, Jarl-Thure; Harjunen, Pirkko; Heikinheimo, Riikka; Karjalainen, Sakari; Kekkonen, Timo; Neittaanmäki, Petri; Ormala, Erkki; Peltonen, Petri; Pöysti, Kaija; Strengell, Merja; Stenros, Anne; Teperi, Juha; Toivanen, Hannes (2008): Government's Communication on Finland's National Innovation Strategy to the Parliament

[14] Watts, Frances; García-Carbonell, Amparo; Andreu-Andrés, $\mathbf{M}^{\mathrm{a}}$ Ángeles; Stange, Christiane \& Helker, Helmut (2013), pp. 44-56. ASSESSMENT OF INNOVATION COMPETENCE. In Lehto, Anttoni and Penttilä, Taru (ed) (2013): Pedagocical views on innovation competences and entrepreneurship. Innovation pedagogy and other approaches. Reports from Turku University of Applied Sciences 171 